\title{
Sansón Carrasco: Un personaje clave en el Quijote de 1615. ¿Representa en él Cervantes a Avellaneda?
}

\author{
Antonio SÁnchez Portero*
}

Para mejor comprensión de la hipótesis que expongo en este artículo, convendría partir de la premisa de que el autor del Quijote apócrifo, el licenciado Alonso Fernández de Avellaneda, es el licenciado Pedro Liñán de Riaza, a quien se considera toledano, pero es aragonés ${ }^{1}$. Así como «admitir» que Cervantes conocía el Quijote de Avellaneda antes de comenzar a escribir la segunda parte del suyo; que sabía quién era Avellaneda; y así como Avellaneda imitó y se inspiró en Cervantes, este se inspiró e imitó a Avellaneda ${ }^{2}$. Y conocer también los artículos «El autor del Quijote de Avellaneda es Pedro Liñán de Riaza, poeta de Calatayud» y «Cervantes y Avellaneda y, entre ambos Quijotes, Tirso de Molina y Liñán de Riaza» ${ }^{3}$.

Ahora, en el presente artículo, sin tener que repetir lo ya expuesto, voy a completar y reafirmar mi hipótesis con nuevas aportaciones y consideraciones, que me empujan paulatinamente a una mayor convicción de que el desde hace más de tres siglos tan buscado Avellaneda lo tenemos en el íntimo amigo de Lope de Vega, el poeta y autor de comedias Pedro Liñán de Riaza.

* Centro de Estudios Bilbilitanos, Calatayud; de la Institución «Fernando el Católico», del CSIC, Zaragoza.

1. Antonio SÁnchez Portero, «Pedro Liñán de Riaza — candidato a ser Avellaneda - es aragonés, de Calatayud», Revista Electrónica Lemir, n. ${ }^{\circ}$ 11, 2007, pp. 61-78 〈http://parnaseo.uv.es/lemir/Revista/Revista11/Revista11.htm〉.

2. ANTONIO SÁNCHEZ PoRTERo, Tres afirmaciones capitales que deberían promover la reconsideración de algunos análisis y opiniones sobre el Quijote, Biblioteca Virtual Miguel de Cervantes, 2007 〈http://www.cervantesvirtual.com/FichaObra.html?Ref=25581〉.

3. Antonio SÁnchez Portero, ambos artículos publicados en la Biblioteca Virtual Miguel de Cervantes $\langle$ http:/www.cervantesvirtual.com/FichaObra.html?Ref=23433〉 y $\langle$ http:/www.cervantesvirtual.com/FichaObra.html?Ref=23432〉, respectivamente. 
Comenzaremos reparando en que a los personajes llamemos familiares de don Quijote: ama, sobrina, mozo de campo, cura y barbero, se les une, pero en la segunda parte, uno clave: Sansón Carrasco, por lo que puede deducirse que este protagonista surge como consecuencia de la aparición del Quijote de Avellaneda.

La fecha de 1605, en la que se imprime «oficialmente» El Ingenioso Hidalgo Don Quijote de la Mancha, puede considerarse como la de la culminación de la ficción narrativa, de la historia novelada. Diez años después, en 1615, se publica la continuación de la anterior historia con el título de El Ingenioso $\mathrm{Ca}$ ballero Don Quijote de la Mancha. Obsérvese que los dos títulos comienzan con «El» y que en el primero es «Hidalgo» y en el segundo «Caballero».

Pero el tiempo real transcurrido entre una y otra parte (diez años) no se contempla en la narración, pues aunque

... el cura y el barbero se estuvieron casi un mes sin verle [a don Quijote]... ${ }^{4}$,

no por eso dejaron de visitar a su sobrina y a su ama, encargándolas tuviesen cuenta con regalarle (Q. II, 1).

Sin embargo, al final del capítulo II, le comunica Sancho a don Quijote que:

... si vuestra merced quiere saber todo lo que hay acerca de las caloñas [calumnias] que le ponen, yo le traeré luego aquí al momento quien se las diga todas, sin que les falte una meaja, que anoche llegó el hijo de Bartolomé Carrasco, que viene de estudiar de Salamanca, hecho bachiller, y, yéndole yo a dar la bienvenida, me dijo que andaba ya en libros la historia de vuestra merced con el nombre del Ingenioso hidalgo don Quijote de la Mancha, y dice que me mientan a mí en ella con el mismo nombre de Sancho Panza...

Se da por hecho y es comúnmente admitido que Cervantes se refiere a la historia impresa de la primera parte de su Quijote (porque la otra acaba de comenzar y está por realizarse); pero creo que no es así por varios motivos:

Si se tratase de esta parte primera, no viene a cuento, está de más hablar de las «caloñas que le ponen»; también es innecesario, por obvio, aclarar:

... y dice que me mientan a mí en ella [a Sancho] con el mesmo nombre.

¿Con qué otro nombre podrían mentarlo? Ahora bien, esta aclaración está justificada si se refiere al apócrifo de Avellaneda, publicado en 1614, aunque desde mucho antes circulaba como manuscrito.

Pero, a pesar de su sutileza, hay un detalle que delata a Cervantes, cuando dice:

... que andaba ya en libros la historia de vuestra merced con el nombre 'del' Ingenioso Hidalgo...

4. Don Quijote de la Mancha, Edición del IV Centenario de la Real Academia Española, F. Rico (ed.), Madrid, 2005. 
Resulta que su primera parte se titula «El» Ingenioso Hidalgo... y la segunda, que en la narración está por concluirse, y por tanto no puede ser impresa, «El»Ingenioso Caballero... Siempre encabeza el título de su obra con la palabra «El». Sin embargo, al referirse aquí al Quijote, lo titula «del Ingenioso Hidalgo...», y se da la circunstancia de que el libro de Avellaneda se titula Segundo Tomo «del» Ingenioso Hidalgo...

En muchas ocasiones, Cervantes es premeditadamente ambiguo y, en este capítulo, a mi modo de ver, juega a confundir al lector al referirse a su Quijote ya publicado, al de Avellaneda, o a los dos. Dice Cervantes que el suyo fue

... compuesto por Cide Hamete Benengeli, historiador árabe, y traducido por un morisco,

a quien se refiere en otros capítulos con las siguientes expresiones: "como tú, sabio encantador, quien quiera que seas, a quien ha de tocar ser el coronista» de su historia; «cuenta el sabio»; «autor arábigo y manchego»; «el sabio y atento historiador».

Y Avellaneda, en el suyo, para no ser menos, dice que

fue compuesto por el sabio Alisolán, historiador no menos moderno que verdadero.

Así como creo que Cide Hamete Benengeli es un anagrama de Miguel de Cervantes ${ }^{5}$, sospecho con fundamento que Avellaneda, o sea Liñán, en la imitación recíproca en la que se embarcaron, inventa también su historiador sabio, bautizándolo con un anagrama incompleto de su apellido. Vemos que en ALISOLÁN se encuentran las letras de LIÑÁN, menos la «Ñ» (si la hubiese puesto, el misterio, el enigma, dejaría de serlo) y añade una «A» para formar «ALI», un nombre árabe. Pero Cervantes bien sabe que Avellaneda, el «fingido tordesillesco», el «autor aragonés» es cristiano.

Los dos son historiadores y sabios, y partiendo de esta coincidencia se aprovecha Cervantes para que con su habitual y premeditada anfibología pase inadvertida su alusión al Quijote de Avellaneda:

—Yo te aseguro, Sancho — dijo don Quijote—, que debe de ser algún sabio encantador el autor de nuestra historia; que a los tales no se les encubre nada de lo que quieren escribir.

- $\mathrm{Y}$ ¡cómo — dijo Sancho - si era sabio y encantador, pues (según dice el bachiller Sansón Carrasco, que así se llama el que dicho tengo) que el autor de la historia se llama Cide Hamete Berenjena!

-Ese nombre es de moro — respondió don Quijote.

[... Quien dice:]... que me tiene suspenso lo que me has dicho, y no comeré bocado que bien me sepa hasta ser informado de todo. 
Y esta información se produce en el capítulo III, que trata «Del razonamiento que pasó entre don Quijote, Sancho Panza y el bachiller Sansón Carrasco». Estaba pensativo don Quijote, esperando las buenas nuevas que le diese el bachiller, cuando:

... con todo esto imaginó que algún sabio, o ya amigo o enemigo, por arte de encantamiento las había dado a la estampa [la segunda parte de sus historias, el Tomo segundo de Avellaneda, porque las «suyas» las estaba «escenificando» y no podían haber llegado a la imprenta]; si amigo, para engrandecerlas y levantarlas..., si enemigo para aniquilarlas y ponerlas debajo de las más viles que de algún vil escudero se hubieran escrito, puesto - decía entre sí- que nunca hazañas escuderiles se escribieron... ${ }^{6}$

Y varios párrafos más adelante:

Una de las cosas — dijo a esta sazón don Quijote — que más debe de dar contento a un hombre virtuoso y eminente [a Cervantes] es verse, viviendo, andar con buen nombre por las lenguas de la gente, impreso y en estampa. Dije con buen nombre, porque siendo contrario, ninguna muerte se le igualara.

Considero una redundancia el término «viviendo», ¿no estará pensando Cervantes en que Avellaneda-Liñán estaba muerto y no tenía, no quería que tuviese «buen nombre»?

- Si por buena fama y si por buen nombre va — dijo el bachiller-, sólo vuestra merced lleva la palma de todos los caballeros andantes; porque el moro en su lengua [Cide Hamete-Cervantes] y el cristiano en la suya [Alisolán-Avellaneda-Liñán] tuvieron buen cuidado de pintarnos muy al vivo la gallardía de vuestra merced, el ánimo grande en acometer peligros, la paciencia en las adversidades y el sufrimiento así en las desgracias como en las heridas, la honestidad y continencia en los amores tan platónicos de vuestra merced y de mi señora doña Dulcinea del Toboso.

Es innegable que Cervantes habla de los dos Quijotes, pero al final del párrafo, con la cita de Dulcinea, se difumina y enmascara lo que es patente. Gran habilidad tiene para decir algo y que pase inadvertido lo dicho para los profanos. De esta ambigüedad hace gala Cervantes cuando Carrasco, hablando de la historia de don Quijote, dice:

... pero quisiera yo que tales censuradores fueran más misericordiosos y menos escrupulosos, sin atenerse a los átomos del sol clarísimo de la obra que murmuran...

—El que de mí trata — dijo don Quijote—, a pocos habrá contentado.

6. Este sería el lugar idóneo para ampliar la información sobre este punto con noticias recién recabadas de Maldonado de Guevara (véase nota 7), cuando ya había dado por concluido este artículo. Pero, para no romper la estructura de estos párrafos o reelaborarlos, no veo inconveniente en incorporar los nuevos datos a continuación. 
Aquí Cervantes seguro que no se refiere a «su» libro, al que poco antes ha alabado, por boca de Sansón Carrasco, quien refiriéndose a él, dice:

... que en el día de hoy están impresos más de doce mil libros de la tal historia; si no, dígalo Portugal, Barcelona y Valencia, donde se han impreso; y aun hay fama de que se está imprimiendo en Amberes, y a mí se me trasluce que no ha de haber nación ni lengua donde no se traduzca.

\section{En el capítulo XVI dice don Quijote:}

... y así, por mis valerosas, muchas y cristianas hazañas he merecido andar ya en estampa en casi todas o las más naciones del mundo. Treinta mil volúmenes se han impreso de mi historia, y lleva camino de imprimirse treinta mil veces de millones, si el cielo no lo remedia.

\section{Y en el VII, expone:}

Mal se te acuerdan a ti, ¡oh Sancho!, aquellos versos de nuestro poeta donde nos pintan las labores que hacían allá en sus moradas de cristal aquellas cuatro ninfas que del Tajo amado sacaron las cabezas y se sentaron a labrar en el prado aquellas ricas telas que allí el ingenioso poeta nos describe, que todas eran de oro, sirlo y perlas contestas y tejidas. Y desta manera debía de ser el de mi señora cuando tú la viste; sino que la envidia que algún mal encantador debe de tener a mis cosas, todas las que me han de dar gusto trueca y vuelve en diferentes figuras que ellas tienen; y así, temo que en aquella historia que dicen que anda impresa de mis hazañas, si por ventura ha sido su autor algún sabio mi enemigo [Alisolán-Liñán], había puesto unas cosas por otras, mezclando con una verdad mil mentiras, divirtiéndose a contar otras acciones fuera de lo que requiere la continuación de una verdadera historia. [Sin duda se está refiriendo Cervantes al Quijote de Avellaneda, fruto de la envidia.] ¡Oh envidia, raíz de infinitos males y carcoma de las virtudes! Todos los vicios, Sancho, traen un no sé qué de deleite consigo; pero el de la envidia, no trae sino disgustos, rencores y rabias.

Me complace sobremanera comprobar que, en 1950, compartía esta opinión Francisco Maldonado de Guevara, quien en El incidente Avellaneda ${ }^{7}$, expuso:

Entre el capítulo primero y el octavo de la segunda parte del Quijote debe mediar, cuanto a la composición, un lapso muy apreciable de tiempo. No sé si meses o años. Al llegar Cervantes al dicho capítulo octavo estaba ya engrosado, y aun henchido para estallar, el cúmulo de noticias allegadas por Cervantes acerca de la obra en gestación de Avellaneda. Todavía desconoce

7. Francisco Maldonado de Guevara, «El Incidente Avellaneda», Revista de Ideas Estéticas, 31, 1950; y Anales Cervantinos, V, 1956-1957, pp. 41-62. Aunque el candidato que propone «para aclarar el misterio del Quijote apócrifo» es Alfonso Pérez de Montalbán, la argumentación aportada aquí es válida para confirmar que en este pasaje se refería Cervantes al Quijote de AvELLANEDA. 
el seudónimo de su contradictor; pero de él habla y a él se dirige Don Quijote, sin duda alguna, al sospechar que la historia que anda impresa de sus hazañas puede ser obra de algún encantador, su enemigo. El referirse Cervantes expresamente a la historia ya impresa ha de divertir la mirada del lector y del crítico, puesta por fuerza o por costumbre en la primera parte de 1605 . Pero aquí hay un equívoco oscurecido y univocado por el humor festivo e irónico de Cervantes. El encantador enemigo de la obra. Sobre este presupuesto queda claro todo el párrafo, con toda la riqueza de alusiones y de intenciones que contiene. El párrafo es largo, pero no puedo dejar de copiarlo en su integridad. En él aparece la envidia como móvil de una mala acción literaria y publicista, y asimismo aparece un dicterio contra los judíos formulado en una forma feroz y rotunda, completamente insólita en Cervantes:

«Temo — dice Don Quijote - que en aquella historia que dicen que anda impresa de mis hazañas, si por ventura ha sido su autor algún sabio, mi enemigo, habrá puesto unas cosas por otras, mezclando con una verdad mil mentiras, divirtiéndose a contar unas acciones fuera de lo que requiere la continuación de una verdadera historia; ;oh, envidia, raíz de infinitos males y carcoma de las virtudes! Todos los vicios, Sancho, traen un no sé qué de deleite consigo; pero el de la envidia no trae sino disgustos, rencores y rabias».

Bien se ve que ahora, a raíz de haber hablado de la historia ya impresa habla de la continuación de la historia. A ella se refiere con el calor de la cólera que le lleva a gritar una invectiva retórica contra la envidia, la cual recuerda, por cierto, las entonadas sin reposo a lo largo de su vida por Lope de Vega.

Y concluye su artículo Maldonado de Guevara con el siguiente párrafo que, por razones obvias, no hace falta decir que su final no comparto:

Mucha maña se dio el encantador Avellaneda en el juego de pseudónimos contra sinónimos para cantar el triunfo del anónimo que ha llegado encapotado hasta nuestros días. Pero a esa maña contribuyó con él, en aparente amigable consorcio, el silencio del propio Cervantes. Y este es el enigma que ha de seguir perdurando a pesar de críticos, de comentaristas y de historiadores, más encantados que encantadores en su inmovilidad y en su impotencia para resolverlo.

\section{Al final del capítulo IV hay un diálogo que puede tener especial y extraor- dinaria importancia:}

—Dios lo haga — dijo don Quijote [respondiendo a Sancho]—, y ello dirá cuando el gobierno venga; que ya me parece que le trayo entre los ojos.

Dicho esto, rogó al bachiller que, si era poeta, le hiciese merced de componerle unos versos que tratasen de la despedida que pensaba hacer de su señora Dulcinea del Toboso, y que advirtiese que en el principio de cada verso había de poner una letra de su nombre, de manera, que al fin de los versos, juntando las primeras letras, se leyese: «Dulcinea del Toboso».

-El bachiller respondió que puesto que él no era de los famosos poetas que había en España, que decían que no eran sino tres y medio, que no dejaría de componer los tales metros, aunque hallaba una dificultad grande en 
su composición a causa que las letras que componían el nombre eran diez y siete, y que si hacía cuatro castellanas de a cuatro versos, sobraba una letra, y si de a cinco que llaman «décimas» o «redondillas», faltaban tres letras: pero con todo eso procuraría embeber una letra lo mejor que pudiese, de manera, que en las cuatro castellanas se incluyese el nombre de Dulcinea del Toboso.

- Ha de ser así en todo caso - dijo don Quijote-; que si no va el nombre patente y de manifiesto, no hay mujer que crea que para ella se hicieron los metros.

Quedaron en esto, y en que la partida sería de allí a ocho días...

No es normal que don Quijote «le pida al bachiller unos versos prestados, cuando él presumía de saber hacerlos (I, 23), y los había hecho (I, 26) y aún volvería a hacerlos en adelante (II, 46)» ${ }^{8}$. El bachiller respondió «... que no dejaría de componer los tales metros, aunque hallaba una dificultad grande, a causa de que las letras que contenía el nombre eran diecisiete».

En efecto, este es el número de letras de «Dulcinea del Toboso». Pero no es menos cierto que lo es también el de «Pedro Liñán de Riaza». Dice López Navío en otra de sus notas (n. ${ }^{\circ} 63$ ) que «don Quijote pedía al bachiller un acróstico, uso bastante extendido en aquellas calendas. Algunos de estos acrósticos han servido para identificar a los autores de algunas obras». ¿Nos encontramos aquí en este caso? Porque no hay que olvidar que Sansón Carrasco es bachiller, estudió en Salamanca, viste el hábito de San Pedro y es poeta; lo mismo que el bachiller Liñán, que estudió Cánones en Salamanca y era poeta famoso. No es la primera vez que Cervantes establece este paralelismo. Una, o hasta varias veces, podría ser casualidad, pero tantas y tantas, en ocasiones despotricando contra determinados licenciados y poetas, tienen que obedecer a otros motivos.

A mayor abundamiento, el Sansón Carrasco que aquí dice - transmitiendo el pensamiento de Cervantes- «que él no era de los famosos poetas que había en España», este mismo Sansón, en el capítulo LXXIII, se expresa de la siguiente manera:

Y más — dijo Sansón Carrasco—, que como ya todo el mundo sabe, yo soy celebérrimo poeta, y a cada paso compondré versos pastoriles o cortesanos o como más me viniere a cuento, para que nos entretengamos por estos andurriales donde habemos de andar...

Y López Navío, en la nota 24 de este capítulo, expone:

celebérrimo poeta: Los comentadores creen que es un chiste socarrón, del bachiller, pero no se trata de una bufonada, sino de una realidad. Si Sansón Carrasco simboliza a Liñán (muerto ya, pero Cervantes había de se-

8. Miguel de Cervantes, El ingenioso hidalgo don Quijote de la Mancha, José Luis Pérez LóPEZ (ed.) (con las «Notas al Quijote» de José LóPeZ NAvío) [Toledo], Empresa Pública Don Quijote de la Mancha, 2005, cap. IV, n. 62. El contenido de esta nota se lo atribuye López Navío a Clemencín. 
guir la ficción primitiva) hay que reconocer que era «celebérrimo poeta», muy admirado de Lope de Vega, y que formó la escuela de los «aliñanados» (atildados y amanerados). Don Quijote en II, 67 dice que era «poeta en extremo».

Coincido con Eduardo Godoy Gallardo 9 en que Sansón Carrasco es un personaje clave que, a pesar de su importancia y siendo trascendente su aportación, no ha sido estudiado individualmente en el Quijote de 1615. Cuatro son sus apariciones fundamentales. En la primera (caps. 2, 3, 4 y 7), a la que ya nos hemos referido, saca a relucir las hazañas de don Quijote que andaban impresas, y convence a este para que inicie una nueva salida, con el objeto de salirle al paso y vencerlo, para imponerle que se olvide de sus aventuras. Para ello se encarna en el Caballero del Bosque (caps. 12 al 16), a quien en una ocasión nombra como Caballero de la Selva, y, poco antes del combate es transformado en Caballero de los Espejos.

Estos nombres y este cambio tendrán su significado y obedecerán a algún motivo - porque nada deja Cervantes al azar- pero no acierto a entenderlo, salvo que sea un despiste del autor, por cierto de mucho bulto. El capítulo XII se titula: «De la extraña aventura que le sucedió al valeroso don Quijote con el bravo Caballero de los Espejos». Sin embargo, en este capítulo interviene el Caballero del Bosque, como en el siguiente, «Donde se prosigue la aventura del Caballero del Bosque, con el discreto, nuevo y suave coloquio que pasó entre los dos escuderos». Y es en el XIV, titulado exactamente «Donde se prosigue la aventura del Caballero del Bosque», cuando se efectúa el cambio de denominación:

Don Quijote miró a su contendor y hallóle ya puesta y calada la celada, de modo que no le pudo ver el rostro, pero notó que era hombre membrudo, y no muy alto de cuerpo. Sobre las armas traía una sobre vista o casaca de una tela, al parecer de oro finísimo, sembradas por ella muchas lunas pequeñas de resplandecientes espejos, que le hacían en grandísima manera galán y vistoso; volávanle sobre la celada grande cantidad de plumas verdes, amarillas y blancas; la lanza que tenía arrimada a un árbol era grandísima y gruesa, y de un hierro acerado de más de un palmo.

Todo lo miró y todo lo notó bien don Quijote y juzgó de lo visto y mirado que el ya dicho caballero debía ser de grandes fuerzas; pero no por eso temió como Sancho Panza, antes con gentil denuedo dijo al Caballero de los Espejos:

—Si la mucha gana de pelear, señor caballero...

A partir de aquí, y en el capítulo siguiente, el protagonista es el Caballero de los Espejos, un Sansón que resultó vencido y que comenzó a pensar en vengarse de la derrota.

9. Eduardo Godoy Gallardo, «Presencia y sentido de Sansón Carrasco», Revista Chilena de Literatura, 67, 2005, pp. 53-67. 
Sería interesante analizar con lupa el contenido de los capítulos del Caballero del Bosque y del Caballero de los Espejos considerando o dando por cierto que Sansón es Liñán y este a su vez Avellaneda. Es posible que se encuentre algún hilo, alguna revelación, que arroje luz sobre el intrincado misterio de la autoría del Quijote apócrifo. Por ejemplo, dirigiéndose a Tomé Cecial, el escudero del Caballero del Bosque:

—Debe ser — dijo Sancho — su amo de vuestra merced, caballero a lo eclesiástico, y podrá...

Y en la nota 9 del capítulo XIII puntualiza López Navío:

a lo eclesiástico: «Como el arzobispo Turpín y otros, de que están llenas las historia no fingidas sino verdaderas [...], en España hubo varios prelados que militaron en las guerras civiles de Castilla (Carrillo, Mendoza, Acuña) [...], es de notar que el bachiller Carrasco, amo de Tomé Cecial, estudiaba para clérigo o por lo menos vestía el hábito de San Pedro» (Clemencín). Pero, ¿a quién quiere aludir Cervantes en estos dos personajes. Para mí que alude a dos personas vivientes, contemporáneas del ilustre manco.

Por cierto, que cuando Cervantes, en el capítulo LIX, reconoce explícitamente la existencia de la «Segunda Parte de don Quijote de la Mancha», de un autor «fingido y tordesillesco», coincidiendo don Quijote y Sancho en una venta con don Juan y don Jerónimo, antes de la llegada de don Quijote a Barcelona y de su encuentro con el de la Blanca Luna, los diálogos entre estos personajes en la venta suscitan la siguiente nota muy interesante de López Navío:

\begin{abstract}
50.- el autor: ¡Cuántas conjeturas para descifrar el enigma que encubre el pseudónimo Alonso Fernández de Avellaneda! Lástima que Cervantes no levantase más el velo. No hay duda de que salió del bando de «los discretos», los partidarios de Lope de Vega [...]. Bonilla y San Martín ya sostuvo que el autor del falso Quijote fue Liñán y que es aludido en el bachiller Sansón Carrasco. Lo malo es que lo indica de pasada en las notas a la Historia de la Literatura Española de F. Kelly sin aducir pruebas concretas, sin ampliar luego esas notas en un estudio completo. R. Marín no admite esta teoría, por haber muerto Liñán en 1607. Pero esto que a D. Francisco le parece una dificultad insoluble, me parece a mí que fortalece la opinión. Liñán tendría escrito el falso Quijote, o lo principal por lo menos...
\end{abstract}

Sansón Carrasco, porque así lo dispone Cervantes, venciendo don Quijote, que no combate pero sorprende al Caballero del Bosque o de los Espejos, se prepara a partir de este momento para una tercera aparición bajo el disfraz de Caballero de la Blanca Luna (capítulo LXIV), pero ahora ya no le guiará el deseo de que recobre el juicio sino lisa y llanamente el de vengarse de él. 
He observado que al Caballero de los Espejos quizás lo llame así Cervantes por «la casaca en la que llevaba sembradas muchas lunas pequeñas de resplandecientes espejos...». Esto y el que ahora Sansón sea el Caballero de la Blanca Luna, me empuja a pensar sobre el sentido que pudiera tener la palabra «LUNA», y puestos a especular, no puedo evitar relacionar a Sansón Carrasco con Liñán, natural de Calatayud, y a esta ciudad con la familia de los Luna, en la que Benedicto XIII, el Papa Luna, construyó el Convento de San Pedro Mártir de Dominicos, donde fueron enterrados sus padres, y en cuya iglesia estaba la capilla del Santísimo Rosario, sede de la cofradía del mismo nombre, cofradía y devoción tan reiteradamente citados en el Quijote de Avellaneda. Sobre la verosimilitud de esta elucubración, solo Cervantes podría pronunciarse, y mucho me temo que ahora ya no es posible que lo haga; pero dejó una evidencia de que, al menos, pensó en el Papa Luna, cuando le hace decir al visorrey que estaba con don Antonio Moreno y el Caballero de la Blanca Luna:

- Señores caballeros, si aquí no hay otro remedio sino confesar o morir, y el señor don Quijote está en sus trece, el de la Blanca Luna en sus catorce, a la mano de Dios, y dense.

Y López Navío en la nota 25 del capítulo LXIV aclara:

está en sus trece: Por estar «firme, porfiado, terco». Debió originarse esta frase por la terquedad de Benedicto XIII, el antipapa Luna, que nunca quiso renunciar a la tiara, y siempre estuvo en sus trece.

Puntualizo que no es exacto decir «debió», sino que se originó; y que si me pongo en la mente de Cervantes y pienso cómo relacionar a Sansón-Liñán con Calatayud, de una manera digamos universal y que no se descubra la relación, hubiese pensado en denominar al Caballero con el apelativo Luna, común a un Papa vinculado a esta ciudad.

Cervantes, un maestro consumado en la manipulación de conceptos, que dota a sus expresiones con doble o tercer sentido, es muy capaz de transformar la realidad que vivió en ficción virtual, por lo que no sería nada raro que trasladara sus vivencias al argumento novelístico, estableciendo un paralelismo o antagonismo entre lo vivido y lo imaginado. Es lo que aprecio en todo su Quijote $\mathrm{y}$, por tanto, en los capítulos que nos ocupan: un afán o pretensión de Cervantes de ser notario en su recreación ficticia, y al mismo tiempo que esta fuese como una medicina o antídoto que paliase la indignación, la impotencia y la rabia que sentiría por el ataque y el robo de su adversario.

En la ficción, Sansón Carrasco incita a don Quijote a que realice una nueva salida en pos de aventuras; en la realidad verosímil, Avellaneda (Liñán), con la publicación del apócrifo empuja a Cervantes a una continuación, a una segunda parte de su obra cumbre, en la que el bachiller es un personaje fundamental. 
Así lo aprecia Juan Bautista de Avalle-Arce ${ }^{10}$ en un artículo que comienza de esta manera:

El bachiller Sansón Carrasco tiene unas funciones de inmensa importancia en el Quijote de 1615 que la crítica ha postergado. Quiero asomarme hoy día a alguna de estas complejas funciones que desempeña nuestro bachiller como para alertar a esa eminente asamblea de cervantistas. [...] Los datos que siguen de inmediato, sin embargo, suelen quedar trasconejados en el desván de los recuerdos, pero son de mucha importancia para mi tema. Porque Sansón viene vestido con el hábito de San Pedro (sotana, manteo y bonete negros), que era el traje eclesiástico, también usado por los estudiantes, y el mismo Sansón se encarga de informarnos que él es eclesiástico de órdenes menores. Y es bachiller en cánones por Salamanca.

Y en el primer encuentro que tienen don Quijote y Sansón, Cervantes pone de rodillas a este, que dice:

Déme vuestra grandeza las manos, señor don Quijote de la Mancha [...], que es vuestra merced uno de los más famosos caballeros andantes...

También, en el curso de su narración, experimenta Cervantes el placer virtual de vencer a su contrincante, a su enemigo el Caballero del Bosque o de los Espejos. Sin embargo, «deja» que don Quijote sea vencido por el Caballero de la Blanca Luna, porque así conviene para que su historia llegue al final, en el que Sansón juega un papel primordial.

Como vengo diciendo, la relación entre don Quijote (Cervantes) y Sansón (Avellaneda-Liñán) rebasa los límites de la narración novelística. Se intuye, se percibe que hay un trasfondo, que hay algo más. Lo ha sabido ver Marco Massoni ${ }^{11}$ :

Si bien es cierto que Sansón Carrasco pretende vencer a don Quijote para que éste regrese a su hogar y deje las armas, más cierto es que Sansón Carrasco admira a don Quijote, puesto que su poeticidad es auténtica y además sabe que don Quijote es todo un personaje, famoso y reconocible. Por tanto, el bachiller no sólo busca hacer despertar a don Quijote, sino que busca la fama, el crédito de vencer al más grande de los caballeros andantes, porque sabe que don Quijote es un poeta en vida, un poema viviente. Podemos entender que en definitiva el duelo entre don Quijote y el Caballero de los Espejos (del Bosque) es un duelo poético, donde se enfrentan dos poetas, uno viviente y otro escribiente.

Y ahora voy a pasar a un punto que considero tiene su importancia. Como expongo en el libro La identidad de Avellaneda, el autor del otro Quijote y en

10. Juan Bautista de Avalle-Arce, «La poética y el bachiller Sansón Carrasco», Anuario Filosófico, 31, 1998, pp. 395-407.

11. Marco Massoni-Oyarzun, Simbiosidad poética del Quijote [en línea], Editorial Trompe, 16 de marzo de 2007 〈ttp://edtrompe.blogspot.com〉. 
el artículo «Tres afirmaciones capitales...», citados: creo haber encontrado correlación entre Sansón y Liñán a través de la carta que envía Teresa Panza a Sancho:

Unas bellotas envié a nuestra señora la duquesa; yo quisiera que fueran de oro; envíame tú algunas sartas de perlas, si se usan en esa ínsula.

[...] Las nuevas deste lugar son que la Berrueca casó a su hija con un pintor de mala mano [...]. El hijo de Pedro Lobo se ha ordenado de grados y corona [de tonsura y de las cuatro primeras órdenes. Pedro Liñán se ordenó de clérigo presbítero en 1601] con atención de hacerse clérigo; súpolo Minguilla, la nieta de Mingo Silbato, y hale puesto demanda de que la tiene dada palabra de casamiento; malas lenguas quieren decir que ha estado encinta dél, pero él lo niega a pies juntillas.

Tenemos un «Pedro» y la inicial del apellido «Lobo» es una «L», la misma que el de «Liñán»; y no hay que olvidar que la Dulcinea de Avellaneda es Bárbara de Villalobos ${ }^{12}$, y por si faltaba algo para descifrar esta alusión, no tenemos sino preguntar precisamente a Minguilla, que es la protagonista del poema titulado «Burlas» de Pedro Liñán ${ }^{13}$, que comienza: «Contenta estaba la Minguilla», y cuenta los amores de una doncella que se dejó seducir.

Y a su vez, un párrafo de la carta se relaciona con otro que se encuentra en el Prólogo:

... y siquiera no haya emprentas en el mundo, y siquiera se impriman contra mí más libros que tiene las letras de Mingo Revulgo.

La clave la aporta López Navío en la nota 26 del Prólogo: «Son treinta y dos coplas en las que se critica el gobierno desastroso de Enrique IV (Candaulo) en un diálogo entre Mingo Revulgo (el pueblo) y Gil Arribato (profeta o adivino)». Como vemos, incluye Cervantes a «Mingo Revulgo» en el contexto de «se impriman contra mí más libros...». Y en la carta aparece el mismo

12. En su magnífica edición del Quijote de Avellaneda (Madrid, Biblioteca Nueva, 2000), LuIS Gómez CANSECo transcribe Bárbara de «Villatobos». Al comunicarle que en varias ediciones que he usado, una de ellas la de DANIEL CORTEZO, 1884, consta "Villalobos», me contestó que «Desde el punto de vista editorial, estoy convencido de que ha de leerse "Villatobos", ya que sería lectio facilior y a la que acudiría de inmediato un componedor o un copista. Si he mantenido "Villatobos" en la transmisión textual es porque es casi con seguridad absoluta la lectura del texto original de Avellaneda». Y en dicha edición; «641,22: Villatobos A: Villalobos CMG. Aunque pudiera tratarse de una errata, no hay ningún criterio definitivo a favor; sobre todo existiendo el toponímico Villatobas en la provincia de Toledo». También existe el toponímico Villalobos en la provincia de Zamora. Consultado EnRIQUE SUÁREZ FIGAREDO, autor, entre muchos artículos sobre este tema, de «La verdadera edición príncipe del Quijote de Avellaneda», Revista Electrónica Lemir, n. ${ }^{\circ}$ 11, cit., pp. 79-102, es de la misma opinión que Gómez CAnseco. Posteriormente, he podido comprobar en Internet, consultando un facsímil de una de las primeras ediciones que, sin lugar a dudas, es «Villatobos».

13. Poesías de Pedro Liñán de Riaza, Julian F. Randolph (ed.), Barcelona, Puvill, 1982, romance satírico-burlesco n. ${ }^{\circ} 49$. 
«Mingo», pero acompañado por el vocablo «Silbato, en vez de Gil Arribato, ¿con la pretensión, quizás, de dejar una pista que ayude a desvelar la identidad del autor que propició que se imprimiera un libro «contra» él? Si fuese así, y cabe la posibilidad, la sutileza de Cervantes alcanzaría límites insospechados.

Con este ejemplo, otros anteriores, y algunos más recogidos en mi libro y artículos publicados sobre este tema pretendo poner de manifiesto que Cervantes mete continuamente cuñas en clave para indicar que conoce al autor del Quijote apócrifo, que bien se encarga de decir que es aragonés. Pero no le interesa desvelar su nombre abiertamente, entre otros motivos, por no inmortalizarlo (como hizo Mateo Alemán con el continuador de su Guzmán de Alfarache, Juan Martí, en un caso similar y contemporáneo); y por temor a las posibles represalias de los colaboradores a posteriori de Liñán, quienes se encargaron de divulgar el manuscrito del apócrifo, de buscarle un seudónimo y de publicarlo ${ }^{14}$, anticipándose a la edición de la Segunda Parte de Cervantes. Estos fueron el íntimo amigo de Liñán, Lope de Vega, familiar del Santo Oficio, y su paisano aragonés, de Teruel, fray Luis de Aliaga, confesor del rey e Inquisidor General.

Volviendo a De Avalle-Arce, en el artículo citado, expone:

Con la punta de la lanza el bachiller Carrasco ha escrito en las arenas de las playas barcelonesas el último capítulo de la historia del caballero andante don Quijote de la Mancha. En este sentido se puede hablar de Sansón como actor subsidiario o secundario del Quijote. Lo que queda de texto después de la derrota barcelonesa es el lento pero inevitable reintegro de don Quijote en el fuero de Alonso Quijano. La historia del caballero andante la concluyó el bachiller salmantino.

Y así vemos que Alonso Quijano el Bueno, en el lecho, cuando está ya cerca su fin, «nombra por albaceas al señor cura y al señor bachiller Sansón Carrasco, que están presentes». Y en el testamento les suplica que:

\footnotetext{
Si la buena suerte les trujere a conocer al autor que dicen que compuso una historia que anda por ahí con el título de Segunda parte de las hazañas de don Quijote de la Mancha ${ }^{15}$, de mi parte le pidan, cuan encarecidamente ser pueda, me perdone la ocasión que sin yo pensarlo le di de haber escrito tantos y tan grandes disparates como en ella escribe, porque parto desta vida con escrúpulo de haberle dado motivos para escribirlos.
}

14. Antonio SÁnchez Portero, «Lope de Vega y Fray Luis de Aliaga: Personajes clave en la publicación del Quijote de Avellaneda y en la elección del seudónimo que encubre a Pedro Liñán de Riaza», Biblioteca Virtual Miguel de Cervantes, noviembre 2007 〈http://www.cervantesvirtual.com/FichaObra.html?Ref= 26353.

15. Es muy curioso. Ahora, desde el capítulo LIX, cuando habla Cervantes del libro de Avellaneda ya publicado y, por tanto, «debiera» conocer su título exacto, lo titula Segunda parte de las hazanas... o Segunda parte de las aventuras..., en vez de Segundo Tomo del Ingenioso Hidalgo don Quijote de la Mancha, «del Ingenioso», como lo titula, sin duda, al referirse a él, cuando simula o quiere dar a entender que no lo conoce. 


\section{En nota a este párrafo, López Navío expone:}

Advierte Clemencín que aquí, por boca de un moribundo restituido a la razón y naturalmente discreto vuelve [Cervantes] a zaherir al falso Avellaneda, y que lo hace «con mucha gracia y sin el acaloramiento de otras veces». Lo hace con gran ironía, y más si el autor fue el bachiller Sansón (Liñán) ya muerto hacía varios años, y por eso dice «si la suerte les trujere a conocer al autor», y con socarrona ironía pide perdón al autor de haber sido la ocasión de «tan grandes disparates como en ella escribe».

El protagonismo de Sansón Carrasco se pone de manifiesto, una vez más, cuando:

Déjanse de poner aquí los llantos de Sancho, sobrina y ama de don Quijote, los nuevos epitafios de la sepultura, aunque Sansón Carrasco puso éste:

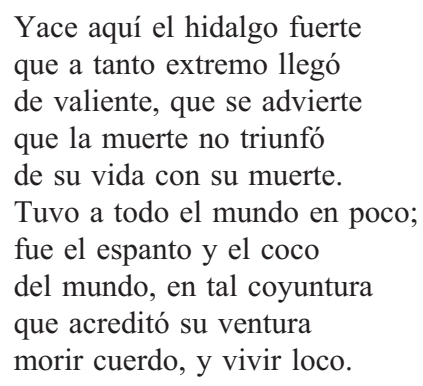

En la nota 61 del último capítulo, comenta López Navío este epitafio:

Yace aqui: «Este epitafio carece de chiste si es de burla, y no es bastante claro si es de veras. De todos modos está muy lejos de corresponder al lugar que ocupa y al objeto que se dirige; y la inscripción puesta sobre el sepulcro de don Quijote debiera ser otra cosa. La dicción es rastrera, los versos desmayados, como casi todos los de Cervantes, y en cuanto a los conceptos, el de la primera quintilla peca de alambicado y falso, y el de la segunda por oscuro. Es desagradable por cierto ver deslucido el final de esta admirable fábula con un insulso epigrama» (Clemencín). Tiene razón el ilustre comentador, pero lo primero que hay que aclarar es si los versos son de Cervantes, o cita a otro autor o lo remeda, hilvanando sus versos en esta poesía. Ya nos dice que el epitafio lo hizo Sansón Carrasco (Liñán, como se ha indicado varias veces), y aunque Liñán tiene mejores versos, se puede admitir que Cervantes lo remeda, copiándole los conceptos y muchos giros. Lo malo es que de Liñán conocemos muy poco; casi toda la producción se ha perdido, y es muy difícil, por ende, hacer un estudio comparativo.

$\mathrm{Y}$ a continuación viene algo que puede tener suma importancia. Al menos, así lo estimo:

... el prudentísimo Cide Hamete, dijo a su pluma: 
-Aquí quedarás colgada desta espetera y deste hilo de alambre, no sé si bien cortada o mal tajada péñola mía, adonde vivirás luengos siglos, si presuntuosos o malandrines historiadores no te descuelgan para profanarte. Pero antes que a ti lleguen, les puedes advertir y decirles en el mejor modo que pudieres:
¡Tate, tate, folloncicos!
De ninguno sea tocada
porque esta empresa, buen rey, para mí estaba guardada.

Para mí sola nació don Quijote, y yo para él; él supo obrar y yo escribir; solos los dos somos para uno, a despecho y a pesar del escritor fingido y tordesillesco que se atrevió, o se ha de atrever, a escribir con pluma de avestruz grosera y mal deliñada ${ }^{16}$ las hazañas de mi valeroso caballero, porque no es carga de sus hombros ni asunto de su resfriado ingenio (II, 74).

Según el Diccionario de la Real Academia, «deliñada» equivale a «compuesta», «aderezada». Lo de «pluma grosera», pase; pero no es lógico que la pluma esté «mal deliñada», o sea, esté «mal compuesta» o «mal aderezada»; pues no debe importar que la pluma sea imperfecta, lo trascendente de verdad es la escritura que realiza o sale de ella. Al usar Cervantes este vocablo, forzando, a mi modo de ver, su exacto sentido, ¿no será porque desea citar sutilmente, de alguna manera a su enemigo Liñán, para dejar constancia de que lo ha descubierto? A este respecto puede ser o no casualidad que, en la segunda parte, emplea Cervantes palabras como adeliñado, socaliñar, adeliñase y adeliño, sobre las que no hay nada que objetar, aunque en alguna ocasión podían sustituirse por otras para simplificar el lenguaje; pero choca y resulta raro que en toda la primera parte no usa Cervantes ninguna palabra de esta familia que, joh casualidad!, mientras la redactaba no había hecho acto de presencia todavía en el escenario quijotesco un otrora amigo y colega llamado Pedro Liñán de Riaza.

A continuación de la cita anterior del texto de Cervantes, que es el párrafo final de su libro, dice:

A quien advertirás [al lector fingido y tordesillesco], si acaso llegas a conocerle, que deje reposar en la sepultura los cansados y ya podridos huesos de

16. José LóPez NAvío, en «Notas al Quijote», expone, en la nota 70 del capítulo LXXIV de la segunda parte: «deliñada: "Así en la primera edición, y en las demás, por yerro de imprenta, debiendo decir: adeliñada, como suele decir Cervantes" (Pellicer). Todas las ediciones posteriores leyeron como Pellicer, menos Cortejón, pero no hace falta apartarse de la lección original, por tener sentido y estar registrada esa palabra en el Dic. Ac.: 'aliñar, componer, aderezar'. Ya se ha indicado otras veces, que Cervantes parece hacer un juego de palabras (adeliñar, adeliño, deliñada) lo que suenan, y [parece ser] una alusión a Liñán (purista y atildado), el supuesto Sansón Carrasco, como se ha dicho en varias ocasiones».

En unos tercetos de El Parnaso, transcritos en Tres afirmaciones capitales..., aparece: «y, como pobre / con este aliño mi jornada sigo». López Navío redactó sus Notas hace más de cincuenta años, y han llegado a mi conocimiento después de que hiciese pública mi opinión sobre este punto en un libro y en varios artículos. Esta coincidencia, así como las relacionadas con que Liñán es Avellaneda me producen una gran satisfacción por mi parte, porque supone que mi razonamiento no es una elucubración gratuita, sino que tiene sustancia y consistencia, o sea, visos de ser una realidad. 
don Quijote [acaba de morir], y no le quiera llevar contra todos los fueros de la muerte, a Castilla la Vieja [se refiere a las aventuras proyectadas por Avellaneda al final del Quijote apócrifo], haciendo salir de la fuesa [fosa] donde real y verdaderamente yace tendido de largo a largo, imposibilitado de hacer tercera jornada y salida nueva; que para hacer burla de tantas como hicieron tantos andantes caballeros, bastan las dos que él hizo, tan a gusto y beneplácito de las gentes a cuya noticia llegaron, así en estos como en los extraños reinos. Y con esto cumplirás con tu cristiana profesión [Liñán era sacerdote], aconsejando bien a quien mal te hizo, y yo quedaré satisfecho y ufano de haber sido el primero que gozó el fruto de sus escritos enteramente, como deseaba, pues no ha sido otro mi deseo de poner en aborrecimiento de los hombres las fingidas y disparatadas historias de los libros de caballerías, que por las de mi verdadero don Quijote van ya tropezando, y han de caer del todo, sin duda alguna.

Vale. FIN.

Estimo que tratándose de un ser de ficción, de don Quijote, es excesivo e inexacto decir «haciéndole salir de la fuesa donde real y verdaderamente yace tendido de largo a largo, imposibilitado de hacer tercera jornada y salida nueva». ¿No querrá más bien referirse Cervantes a Liñán, que bien sabía él se encontraba en la situación que describe? Porque a un ser ficticio se le puede «resucitar» o no darlo por muerto, y continuar la historia.

Abona mi convicción de que Cervantes sabía que Liñán era el autor del otro Quijote lo que aquel aduce a continuación:

Y yo quedaré satisfecho y ufano de haber sido el primero que gozó el fruto de sus escritos enteramente, como deseaba...

¿Por qué dice algo tan obvio? Sabe, como escritor, que algo pudo gozar Liñán de sus escritos mientras los componía, pero no enteramente, pues no pudo verlos publicados.

Observo que es común en Cervantes en el Quijote la parquedad, o mejor aún, la ausencia de rasgos físicos de sus personajes. Así, algunos muy importantes solo merecen los siguientes detalles:

Tenía en su casa un ama que pasaba de los cuarenta, y una sobrina que no llegaba a los veinte, y un mozo de campo y plaza, que así ensillaba el rocín como tomaba la podadera.

Y no es más explícito con otros personajes más o menos secundarios, quienes generalmente son solo un nombre: «Tomé Celial», «Basilio», «Altisidora»; o una profesión: «pescadores», «ventero», «doncella del aguamanil», «sacristán», «virrey»; o ambas en alguna ocasión: «recitantes de la compañía de Angulo el Malo», «Condesa Trifaldi», «lacayo Tosillos»...

Las contadas excepciones las constituyen el propio personaje capital, don Quijote, de quien dice: «era de complexión recia, seco de carnes, enjuto de rostro, gran madrugador y amigo de la caza». Aporta Cervantes alguna breve 
pincelada física de don Diego de Miranda, el Caballero del Verde Gabán: «la edad mostraba de ser de cincuenta años, las canas pocas y el rostro aguileño, la vista entre alegre y grave»; y el del bandolero Roque Guinart: «el cual mostró ser de hasta treinta y cuatro años, robusto, más que de mediana proporción, de mirar grave y color morena».

Más explícito se muestra con Reinaldos de Montalbán (¿Será el editor Juan Pérez de Montalbán?), de quien don Quijote (Q. II, 1) se atreve

a decir que era ancho de rostro, de color bermejo, los ojos bailadores y algo saltados, puntoso y colérico en demasía, amigo de ladrones y de gente perdida. De Roldán, o Rotolando, o Orlando [¿a quien se referirá Cervantes?, porque si esto no son «sinónimos voluntarios», que venga Dios y lo vea], que con todos estos nombres le nombran las historias, soy de parecer y me afirmo que fue de mediana estatura, ancho de espaldas, algo estevado, moreno de rostro y barbitaheño, velloso en el cuerpo y de vista amenazadora, corto de razones, pero muy comedido y bien criado.

Y otra excepción a la regla se materializa en Sansón Carrasco:

Era el bachiller, aunque se llamaba Sansón, no muy grande de cuerpo, aunque muy gran socarrón, de color macilenta, pero de muy buen entendimiento; tendría hasta veinticuatro años, carirredondo, de nariz chata y boca grande, señales todas de ser de condición maliciosa y amigo de donaires y de burlas, como lo mostró en viendo a don Quijote, poniéndose delante del de rodillas, diciéndole...

Si como hemos apuntado Sansón Carrasco es una personificación de Liñán (del Liñán que regresa de Salamanca recién terminados sus estudios de Cánones), puede ser que nos encontremos ante un retrato fidedigno de este poeta a quien se atribuye, con bastantes visos de realidad, ser Avellaneda, el autor del Quijote apócrifo, del otro Quijote.

No sé hasta qué punto sería posible encontrar entre los textos de sus contemporáneos, e incluso hasta en los suyos, algún rasgo físico de Liñán para poder cotejarlo con la descripción de Cervantes. Sería un camino para establecer la identidad de Avellaneda. Otro, en el caso de existir el manuscrito original del Quijote apócrifo (algo que pongo en duda), sería el de cotejarlo caligráficamente con manuscritos originales de Liñán (que pueden existir o descubrirse). Son dos vías difíciles, pero hay que dejar un resquicio abierto a la esperanza.

Lo imposible es que haya un documento que testifique la identidad de Avellaneda, aparte de por otros motivos obvios, porque esta identidad que en su momento sería de dominio, aunque restringido, público, no era susceptible de materializarse en un papel y, con el tiempo, al desaparecer los testigos, se han borrado las huellas.

Por este motivo, a falta de la prueba irrefutable, determinante, fehaciente, opino sinceramente que puede muy bien ser sustituida por el cúmulo de mani- 
festaciones, indicios y testimonios que convierten la hipótesis de que Avellaneda es Liñán en verosímil y apodíctica, una hipótesis que, a tenor de las conjeturas aportadas, resulta difícil de ignorar o de no ser tenida en cuenta.

Recibido: 12-8-2007

Aceptado: 4-4-2008

\title{
Resumen
}

En el Quijote de 1615 aparece Sansón Carrasco, un personaje clave, a mi modo de ver, como consecuencia de la publicación del Quijote apócrifo de Avellaneda. En este artículo defiendo la hipótesis de que Cervantes personifica en Sansón Carrasco a Pedro Liñán de Riaza, y que este es el tan buscado Avellaneda, el autor del otro Quijote, novela que «obligó» a Cervantes a componer la Segunda Parte de la que ha llegado a ser su obra cumbre.

Palabras clave: Sansón Carrasco. Influencia en Cervantes. Avellaneda. El otro Quijote. Pedro Liñán de Riaza.

Title: Sansón Carrasco: a key character in the Quixote of 1615.

Does Cervantes represent Avellaneda in such character?

\begin{abstract}
Sansón Carrasco, who appears in the Quixote of 1615, is in my opinion, a key character, as a result of the publication of Avellaneda's apocryphal Quixote. This article argues for the hypothesis that in Sansón Carrasco, Cervantes personifies Pedro Liñán de Riaza, who is in fact the so much searched Avellaneda, the author of the other Quixote, novel which «obliged» Cervantes to write the Second Part of what has become his most important work.
\end{abstract}

Key words: Sanson Carrasco. Influence on Cervantes. Avellaneda. The other Quijote. Pedro Liñán de Riaza. 